\title{
Investigating the persistence of tick-borne pathogens via the $\mathrm{R}_{0}$ model
}

\author{
A. HARRISON ${ }^{1}$, W. I. MONTGOMERY ${ }^{1}$ and $\mathrm{K}$. J. BOWN ${ }^{2}$ \\ ${ }^{1}$ School of Biological Sciences, Queen's University Belfast, MBC, 97 Lisburn Road, Belfast BT9 7BL, UK \\ ${ }^{2}$ Department of Veterinary Pathology, University of Liverpool, Leahurst Campus, Chester High Road, \\ Neston CH64 7TE, UK
}

(Received 20 October 2010; revised 27 Fanuary 2011; accepted 7 February 2011)

\begin{abstract}
SUMMARY
In the epidemiology of infectious diseases, the basic reproduction number, $\mathrm{R}_{0}$, has a number of important applications, most notably it can be used to predict whether a pathogen is likely to become established, or persist, in a given area. We used the $\mathrm{R}_{0}$ model to investigate the persistence of 3 tick-borne pathogens; Babesia microti, Anaplasma phagocytophilum and Borrelia burgdorferi sensu lato in an Apodemus sylvaticus-Ixodes ricinus system. The persistence of these pathogens was also determined empirically by screening questing ticks and wood mice by PCR. All 3 pathogens behaved differently in response to changes in the proportion of transmission hosts on which I. ricinus fed, the efficiency of transmission between the host and ticks and the abundance of larval and nymphal ticks found on small mammals. Empirical data supported theoretical predictions of the $\mathrm{R}_{0}$ model. The transmission pathway employed and the duration of systemic infection were also identified as important factors responsible for establishment or persistence of tick-borne pathogens in a given tick-host system. The current study demonstrates how the $\mathrm{R}_{0}$ model can be put to practical use to investigate factors affecting tick-borne pathogen persistence, which has important implications for animal and human health worldwide.
\end{abstract}

Key words: tick-borne disease, zoonosis, basic reproduction number, Ixodes ricinus.

\section{INTRODUCTION}

In infectious disease epidemiology, the basic reproduction number, $\mathrm{R}_{0}$, is defined as the average number of secondary cases caused by one infected individual entering a population consisting solely of susceptible individuals (Anderson and May, 1990; Diekmann et al. 1990; Hartemink et al. 2008). $\mathrm{R}_{0}$ has a number of important applications. It has a threshold value such that if $\mathrm{R}_{0}>1$, a pathogen will persist should it be introduced, whilst $\mathrm{R}_{0}<1$ suggests it will die out. $\mathrm{R}_{0}$ is also a measure of the risk that an outbreak may occur and, when an outbreak does occur, it gives a measure of the initial rate of exponential increase of infected individuals. The proportion of a population that requires vaccination in order to prevent an outbreak is also determined using $\mathrm{R}_{0}$ (Anderson and May, 1990; Diekmann et al. 1990; Hartemink et al. 2008). $\mathrm{R}_{0}$, however, is difficult to define in natural systems due to indeterminate variability in susceptibility, infectivity and contact rates among individuals. This problem is often compounded by the presence of multiple host species and transmission routes (Hartemink et al. 2008). Given the importance of $\mathrm{R}_{0}$ in the epidemiology of infectious diseases there have been many attempts to define $\mathrm{R}_{0}$ for tick-borne infections (Randolph, 1998; Norman et al. 1999;

* Corresponding author and present address: Department of Zoology and Entomology, University of Pretoria, Pretoria, 0002, South Africa. Tel: +0027 (0)713815103. E-mail: atharrison@zoology.up.ac.za
Randolph et al. 1999; Caraco et al. 2002; Rosa et al. 2003; Ghosh and Pugliese, 2004; Rosa and Pugliese, 2007). More recently, next generation matrix methods have been employed to address the complexities of infections in natural systems (Hartemink et al. 2008) which has resulted in the most comprehensive and biologically correct estimation of $\mathrm{R}_{0}$ for tick- borne infections.

Tick species of the genus Ixodes are important vectors of numerous pathogens worldwide (Parola and Raoult, 2001). Throughout Europe, I. ricinus is the vector of Babesia microti, Anaplasma phagocytophilum and Borrelia burgdorferi sensu lato, the agents of human babesiosis, human granulocytic anaplasmosis and Lyme borreliosis respectively (Duh et al. 2001; Parola, 2004; Stanzak et al. 2004). To be a competent vector, more than 1 developmental stage of $I$. ricinus must acquire a bloodmeal from a given host species. For trans-stadial transmission, larvae and nymphs that feed on an infected host, develop to the next instar, and infect a new host during their subsequent feed as nymphs or adults, thereby maintaining a cycle of infection. (Randolph and Storey, 1999). In some cases, ticks can also acquire an infection by feeding alongside infected ticks, without the need for systemic infection of the host (Jones et al. 1987; Randolph et al. 1996). In Europe, rodents host both larvae and nymphs of I. ricinus (Milne, 1949; Gern et al. 1998; Liz et al. 2000; Karbowiak, 2004) and are competent transmission hosts of B. microti, A. phagocytophilum and B. burgdorferi s.1. B. microti 
is a small mammal specific pathogen whilst A. phagocytophilum infects both small mammals and large mammals such as deer, although it is thought that separate $A$. phagocytophilum strains exist in discrete small mammal and large mammal cycles (Bown et al. 2009). Members of the B. burgdorferi s.l. complex utilize a range of vertebrate transmission hosts, for example, the $B$. valaisiana genospecies is associated with birds and $B$. afzelii with rodents (Kurtenbach et al. 2002). Deer are not considered competent transmission hosts of B. burgdorferi s.l. (Telford et al. 2006). In some locations, as in Ireland, nymphs of $I$. ricinus may be found in extremely low numbers or be completely absent from small mammals (Gray et al. 1999, 2000; Harrison et al. 2010). This has led to the suggestion that small mammals may not always be important transmission hosts of tick-borne infections (Gray et al. 1999, 2000).

We used empirical data from Ireland, where the incidence of nymphs of $I$. ricinus on small mammals is low, and previously published tick, and pathogen-specific, data to parameterize the $\mathrm{R}_{0}$ model of Hartemink et al. (2008). This model was then used to predict whether infections of $B$. microti, A. phagocytophilum, and B. burgdorferi s.l. were likely to persist in small mammal populations. The model was also used to investigate how changes in the proportion of transmission-competent hosts on which $I$. ricinus had fed, the transmission efficiency of pathogens to and from ticks and hosts, and the abundance of larvae and nymphs on hosts, affects pathogen persistence in small mammals. Predictions of the model were validated by screening small mammals and ticks for pathogens by PCR.

\section{MATERIALS AND METHODS}

\section{Calculation of $R_{0}$}

In the current study, $\mathrm{R}_{0}$ was calculated as a function of $h_{c}$, the proportion of competent hosts on which $I$. ricinus is feeding, for $B$. microti, A. phagocytophilum and B. burgdorferi s.l. using the next-generation matrix method of Hartemink et al. (2008). Each element in the matrix was calculated using previously published tick-related and pathogen-specific parameters and tick-related parameters describing the distribution of life stages of $I$. ricinus on $A$. sylvaticus specific to the current study (Tables 1 and 2). As there is a paucity of literature regarding the transmission efficiency of $B$. microti and A. phagocytophilum from I. ricinus to small mammal hosts $\left(\beta_{\mathrm{T}-\mathrm{V}}\right)$ and from small mammal hosts to $I$. ricinus $\left(\beta_{\mathrm{V}-\mathrm{T}}\right), \mathrm{R}_{0}$ was calculated using low, medium and high transmission efficiency scenarios for these pathogens using transmission coefficients of $0 \cdot 1,0 \cdot 5$, and $0 \cdot 9$ respectively. In the case of $B$. burgdorferi s.l. previously published transmission coefficients were used.
Table 1. Ecological parameters for Ixodes ricinus derived from the literature and the current study (adapted from Hartemink et al. (2008).)

(Numbers in superscript refer to the following sources: ${ }^{1}$ Randolph and Craine (1995), ${ }^{2}$ Randolph (2004), ${ }^{3}$ Current study, ${ }^{4}$ Gray (2002), ${ }^{5}$ Randolph, unpublished. All parameters not taken from the current study were cited by Hartemink et al. (2008). Please refer to the Appendix for equations used to calculate each element within the next generation matrix and for the structure of the matrix.)

\begin{tabular}{|c|c|c|}
\hline Parameter & Description & Estimate \\
\hline$E$ & Eggs per adult & $2000^{1,2}$ \\
\hline$s_{L}$ & $\begin{array}{l}\text { Survival probability from egg to } \\
\text { feeding larvae }\end{array}$ & $0 \cdot 05^{1}$ \\
\hline$s_{N}$ & $\begin{array}{l}\text { Survival probability from feeding } \\
\text { larvae to feeding nymph }\end{array}$ & $0 \cdot 1^{1}$ \\
\hline$s_{A}$ & $\begin{array}{l}\text { Survival probability from feeding } \\
\text { nymph to feeding adult }\end{array}$ & $0 \cdot 1^{1}$ \\
\hline$C_{L L}$ & $\begin{array}{l}\text { Mean number of larvae co-feeding } \\
\text { with a larva }\end{array}$ & $11 \cdot 99^{3}$ \\
\hline$C_{N L}$ & $\begin{array}{l}\text { Mean number of nymphs } \\
\text { co-feeding with a larva }\end{array}$ & $1^{3}$ \\
\hline$C_{A L}$ & $\begin{array}{l}\text { Mean number of adults co-feeding } \\
\text { with a larva }\end{array}$ & $0^{3}$ \\
\hline$C_{L N}$ & $\begin{array}{l}\text { Mean number of larvae co-feeding } \\
\text { with a nymph }\end{array}$ & $47 \cdot 67^{3}$ \\
\hline$C_{N N}$ & $\begin{array}{l}\text { Mean number of nymphs } \\
\text { co-feeding with a nymph }\end{array}$ & $0^{3}$ \\
\hline$C_{A N}$ & $\begin{array}{l}\text { Mean number of adults co-feeding } \\
\text { with a nymph }\end{array}$ & $0^{3}$ \\
\hline$C_{L A}$ & $\begin{array}{l}\text { Mean number of larvae co-feeding } \\
\text { with an adult }\end{array}$ & $0^{3}$ \\
\hline$C_{N A}$ & $\begin{array}{l}\text { Mean number of nymphs } \\
\text { co-feeding with an adult }\end{array}$ & $0^{3}$ \\
\hline$C_{A A}$ & $\begin{array}{l}\text { Mean number of adults co-feeding } \\
\text { with an adult }\end{array}$ & $0^{3}$ \\
\hline$N_{L H}$ & $\begin{array}{l}\text { Average number of larvae on } \\
\text { competent host }\end{array}$ & $7 \cdot 87^{3}$ \\
\hline$N_{N H}$ & $\begin{array}{l}\text { Average number of nymphs on } \\
\text { competent host }\end{array}$ & $0 \cdot 02^{3}$ \\
\hline$N_{A H}$ & $\begin{array}{l}\text { Average number of adults on } \\
\text { competent host }\end{array}$ & $0^{3}$ \\
\hline$D_{L}$ & Days of attachment of larva & $2 \cdot 5^{4}$ \\
\hline$D_{N}$ & Days of attachment of nymph & $3 \cdot 5^{5}$ \\
\hline$D_{A}$ & Days of attachment of adult & $12^{5}$ \\
\hline
\end{tabular}

To investigate what impact the abundance of larval and nymphal stages on hosts may have on the ability of these tick-borne pathogens to become established, or persist, in the current study, $\mathrm{R}_{0}$ was calculated using a fixed value of $h_{c}$ (corresponding to the value obtained for $A$. sylvaticus from bloodmeal analysis) across a range of mean loads of larval and nymphal ticks using a medium level transmission coefficient of 0.5 for B. microti and A. phagocytophilum and previously published transmission coefficients for B. burgdorferi s.1.

$\mathrm{R}_{0}$ was calculated via the spectral decomposition of the parameterized next-generation matrix that yields a set of eigenvalues, the largest of which is $R_{0}$. The matrix was decomposed using the eigen (matrix) function in package base of the $\mathrm{R}$ software 
Table 2. Ecological parameters for B. microti, A. phagocytophilum and B. burgdorferi s.1. (adapted from Hartemink et al. (2008).)

(Numbers in superscript refer to the following sources: ${ }^{1}$ Randolph (1995), ${ }^{2}$ Gray et al. $(2002),{ }^{3}$ Telford et al. (1986), ${ }^{4}$ Hodzic et al. (2001), ${ }^{5}$ Ogden et al. (1998), ${ }^{6}$ Bown et al. (2003), ${ }^{7}$ Randolph et al. (1996), ${ }^{8}$ Gern and Rais (1996), ${ }^{9}$ Randolph and Craine (1995), ${ }^{10}$ Randolph, unpublished, ${ }^{11}$ Kurtenbach et al. (1994), ${ }^{12}$ Hubálek and Halouzka (1998). ${ }^{\text {a Absent or }}$ inefficient co-feeding transmission, ${ }^{\mathrm{b}}$ suggested low, medium and high transmission efficiency scenarios, ${ }^{\mathrm{c}}$ absent or inefficient transovarial transmission. References 7-12 cited by Hartemink et al. (2008). Please refer to the Appendix for equations used to calculate each element within the next generation matrix and for the structure of the matrix.)

\begin{tabular}{lllll}
\hline \hline & Description & B. microti & A. phagocytophilum & B. burgdorferi s.l. \\
\hline$i$ & Systemic infection duration & $2 \cdot 5$ days & 40 days & 120 days $^{3}$ \\
$\theta$ & Efficiency from tick to tick & $0^{\mathrm{a}}$ & $0^{4, \mathrm{a}}$ & $0 \cdot 56^{8}$ \\
$p_{L}$ & Efficiency from competent host to larva & $0 \cdot 1 / 0 \cdot 5 / 0 \cdot 9^{\mathrm{b}}$ & $0 \cdot 1 / 0 \cdot 5 / 0 \cdot 9^{\mathrm{b}}$ & $0 \cdot 5^{9}$ \\
$p_{N}$ & Efficiency from competent host to nymph & $0 \cdot 1 / 0 \cdot 5 / 0 \cdot 9^{\mathrm{b}}$ & $0 \cdot 1 / 0 \cdot 5 / 0 \cdot 9^{\mathrm{b}}$ & $0 \cdot 5^{10}$ \\
$p_{A}$ & Efficiency from competent host to adult & $0 \cdot 1 / 0 \cdot 5 / 0 \cdot 9^{\mathrm{b}}$ & $0 \cdot 1 / 0 \cdot 5 / 0 \cdot 9^{\mathrm{b}}$ & $0 \cdot 4^{11}$ \\
$q_{L}$ & Efficiency from larva to competent host & $0^{1,2}$ & $0^{5,6, \mathrm{c}}$ & $0 \cdot 8^{10}$ \\
$q_{N}$ & Efficiency from nymph to competent host & $0 \cdot 1 / 0 \cdot 5 / 0 \cdot 9^{\mathrm{b}}$ & $0 \cdot 1 / 0 \cdot 5 / 0 \cdot 9^{\mathrm{b}}$ & $0 \cdot 8^{10}$ \\
$q_{A}$ & Efficiency from adult to competent host & $0 \cdot 1 / 0 \cdot 5 / 0 \cdot 9^{\mathrm{b}}$ & $0 \cdot 1 / 0 \cdot 5 / 0 \cdot 9^{\mathrm{b}}$ & $0 \cdot 8^{10}$ \\
$r_{A}$ & Efficiency from adult to egg & $0^{1,2, \mathrm{c}}$ & $0^{5,6, \mathrm{c}}$ & $0 \cdot 1^{12}$ \\
\hline \hline
\end{tabular}

package available under GNU licence from www.rproject.org.

\section{Study sites}

Five sites supporting mixed broadleaf and coniferous woodland sites in Northern Ireland were sampled over 8 weeks from May until July 2007. Sites were selected on the basis that they had resident populations of red deer, Cervus elaphus, (2 sites) or fallow deer, Dama dama, (3 sites) and were therefore likely to have ticks present.

\section{Small mammal samples}

In total, 180 Self-set snap traps were deployed in pairs at $15 \mathrm{~m}$ intervals in vegetation adjacent to forest tracks. Traps were set after $6 \mathrm{pm}$ in the evening and collected before 8 am the following morning. Each mouse was stored separately in a sealed sample bag that was also searched for unattached ticks. Ticks were removed from each mouse using fine forceps and a stiff bristle brush paying particular attention to the margins of the pinna. The total number of ticks was recorded per mouse and identified to species using standard keys (Snow, 1978; Arthur, 1963). Their developmental stage was recorded as larvae, nymph or adult. Blood of mice was sampled by cardiac puncture using a sterile $5 \mathrm{ml}, 21$-gauge syringe and needle, blood was stored in individual $1.5 \mathrm{ml}$ microcentrifuge tubes at $-20^{\circ} \mathrm{C}$ prior to DNA extraction.

\section{Sampling of questing ticks}

The abundance of questing ticks was assessed using a standardized drag sampling technique. A $1 \mathrm{~m} \times 1 \mathrm{~m}$ square piece of towelled material, weighted and spread out with bars at the leading and rear edge was dragged along a $15 \mathrm{~m}$ transect of trackside grass at $1 \mathrm{~ms}^{-1}$ with a total of 20 transects per forest site. Ticks were removed from the drag after each transect using fine forceps and stored in 70\% ethanol. Ticks were identified to species level using standard keys, counted, and the developmental stage recorded. In addition to ticks collected from standardized drag sample transects, additional drag samples were conducted to increase the sample size of ticks available for screening for tick-borne pathogens. All sites were sampled for questing ticks at the same time as small mammal trapping (May, June and July, 2007).

\section{DNA extraction}

DNA was extracted from blood by alkaline digestion (Bown et al. 2003). First, $0.5 \mathrm{ml}$ of $1.25 \%$ ammonia solution was added to $50 \mu$ of blood in a Sure-Lock microcentrifuge tube (Fisher Scientific, Loughborough, UK) and heated to $100{ }^{\circ} \mathrm{C}$ for $20 \mathrm{~min}$. Tubes were centrifuged, opened and heated until half the initial volume remained. The solution was diluted 1 in 10 with sterile, deionized distilled water. The same method was used to extract DNA from ticks that had first been macerated using a pipette tip. DNA extracts of ticks were not diluted. Only nymphal and adult ticks were tested for the presence of pathogens.

\section{Detection of pathogens via polymerase chain reaction (PCR)}

An Apicomplexa-specific PCR targeting the 18S rRNA gene was used to test for the presence of Babesia microti (Simpson et al. 2005). A. phagocytophilum and B. burgdorferi s.l. infections were detected using a real-time PCR assay as previously described by Courtney et al. (2004). Samples positive for A. phagocytophilum were subjected to a second, 
nested PCR assay targeting the $m s p 4$ gene for sequence determination (De La Fuente et al. 2005; Bown et al. 2007). Samples positive for B. burgdorferi s.l. were subjected to a second, nested PCR targeting the $5 \mathrm{~S}-23 \mathrm{~S}$ intergenic spacer region (Rijpkema et al. 1995). All PCRs included negative controls in a ratio of 1:5 and positive controls. Amplification products were purified using a Qiaquick PCR purification kit (Qiagen) and sequences determined using a commercial sequencing service (Macrogen, Korea). Sequence data from successfully sequenced amplification products were used to search for other closely related sequences using the NCBI nucleotide BLAST database. Sequences were aligned and compared using BioEdit v7.0.9@ (Ibis Biosciences, California, USA).

\section{Bloodmeal analysis}

Bloodmeal analysis, to identify hosts that questing I. ricinus nymphs had fed on as larvae, was conducted using a published reverse line blot (RLB) protocol (Humair et al. 2007). Five probes were used ('Apodemus', 'bird', 'Capreolus', 'Sciurus' and 'Sorex') as they represent the most likely vertebrate hosts present at study sites, targeting Apodemus sylvaticus, birds, deer, squirrel spp. and Sorex minutus respectively.

\section{RESULTS}

\section{The basic reproduction number, $R_{0}$}

Values of $\mathrm{R}_{0}$ plotted as a function of $h_{c}$ (the proportion of competent hosts on which $I$. ricinus is feeding), for B. microti, $A$. phagocytophilum and B. burgdorferi, s.1. are presented in Fig. 1 .

In the case of B. microti, the threshold value for $\mathrm{R}_{0}$ was never reached regardless of the proportion of competent hosts on which $I$. ricinus had fed or the transmission efficiency scenario employed. This was also the case for $A$. phagocytophilum under low transmission efficiency. However, for medium and high transmission scenarios the proportion of competent hosts on which $I$. ricinus was required to feed upon in order for the threshold value to be reached were $30 \%$ and $9 \%$ respectively. When $h_{c}$ was fixed at $11.45 \%$ (representing 11 out of 96 positive reactions obtained for $A$. sylvaticus during bloodmeal analysis) the transmission coefficient required to produce a value of $\mathrm{R}_{0}>1$ for $A$. phagocytophilum was $0 \cdot 795$. In contrast, the threshold value of $\mathrm{R}_{0}$ was rapidly achieved for $B$. burgdorferi s.1. with only $2 \cdot 55 \%$ of competent hosts required to be feeding $I$. ricinus for the threshold to be reached.

A plot of the interaction between mean number of larvae and nymphs on a competent host and $\mathrm{R}_{0}$ for each pathogen is presented in Fig. 2. In the case of $B$. microti, increasing the mean number of larvae and nymphs on the host slowly increased the value of $\mathrm{R}_{0}$, but even at unrealistically high tick burdens (80 larvae and 80 nymphs) the threshold value of $R_{0}$ was not reached. In the case of $A$. phagocytophilum, however, the threshold value was achieved much more rapidly, requiring, only a single larvae and 30 nymphs or 20 larvae and a single nymph for the threshold value to be achieved. Similarly, in the case of $B$. burgdorferi s.l. the value of $\mathrm{R}_{0}$ increased rapidly with increasing tick load, requiring only a single larvae and a single nymph for the threshold value of $\mathrm{R}_{0}$ to be reached.

\section{Tick distribution}

A total of 233 questing ticks consisting of 100 larvae, 129 nymphs and 4 adults were collected from standardized drag samples. The only tick species identified was $I$. ricinus. Densities were generally low with a mean abundances per $\mathrm{m}^{2} \pm \mathrm{s}$.E. for larvae, nymphs and adults of $0 \cdot 086 \pm 0 \cdot 019,0 \cdot 067 \pm 0 \cdot 014$, and $0 \cdot 003 \pm 0 \cdot 001$ respectively. A total of 1168 ticks consisting of 1165 larvae, 3 nymphs and 0 adults were collected from wood mice, giving an overall nymph:larvae ratio of 1:388. Again, the only tick species recovered was $I$. ricinus. Mean tick burdens per mouse \pm s.E. for larvae, nymphs and adults were $7 \cdot 871 \pm 1 \cdot 087,0 \cdot 020 \pm 0 \cdot 011$ and 0 respectively. The distribution of ticks on wood mice was overdispersed, with a small proportion of the host population $(20 \%)$ feeding the majority of larvae (72\%) and all nymphs.

\section{Pathogen detection}

In addition to the 100 nymphs and 4 adult ticks collected by standardized drag samples, a further 167 nymphs and 6 adults were collected by nonstandardized drags. In total, 137 wood mice and 277 ticks (267 nymphs and 10 adults) were tested for the presence of $B$. microti and A. phagocytophilum whilst the 277 ticks were also tested for $B$. burgdorferi s.1. Three $I$. ricinus nymphs tested positive for the presence of $A$. phagocytophilum but no wood mice or adult ticks were positive. Of the 277 ticks screened for the presence of $B$. burgdorferi s.1. 20 nymphs were positive. No samples were positive for the presence Babesia microti.

\section{Sequence analyses}

(a) A. phagocytophilum. Of the 3 tick samples that tested positive for A. phagocytophilum, 2 (R14 and R49) were sequenced successfully. R14 and R49 were not identical but shared $96 \cdot 3 \%$ similarity. R14 was identical to a strain found in a dog in Slovenia (GenBank Accession no. EF442004), whilst R49 was most closely related to strains recovered from red 


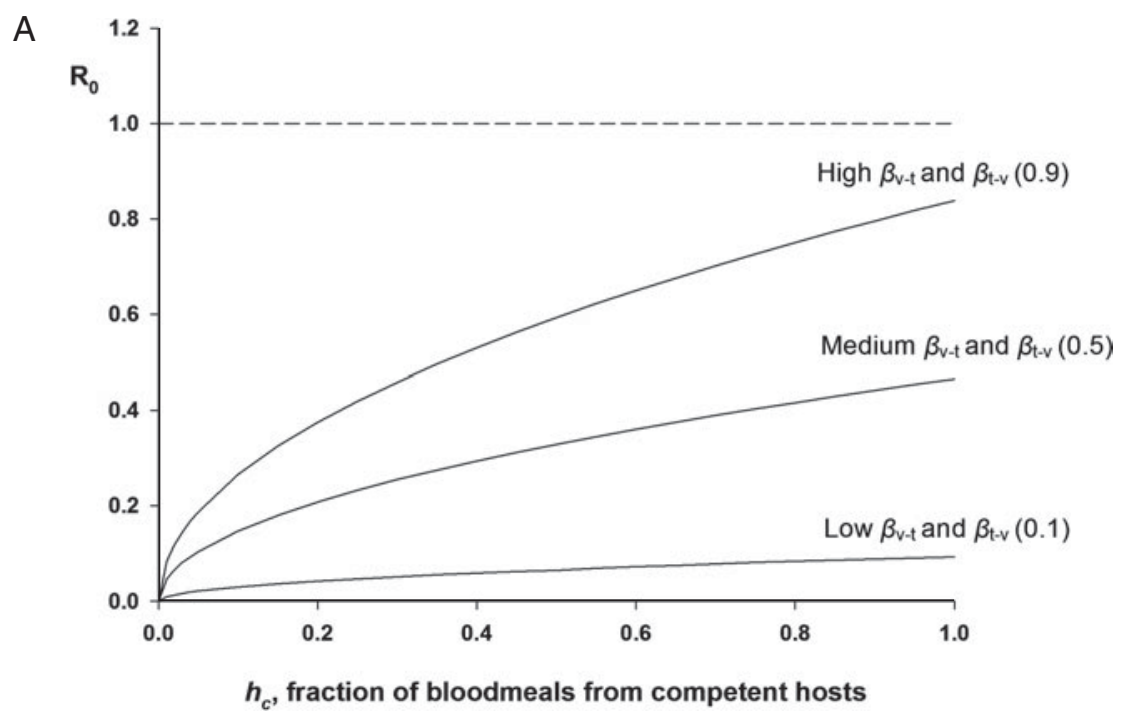

B

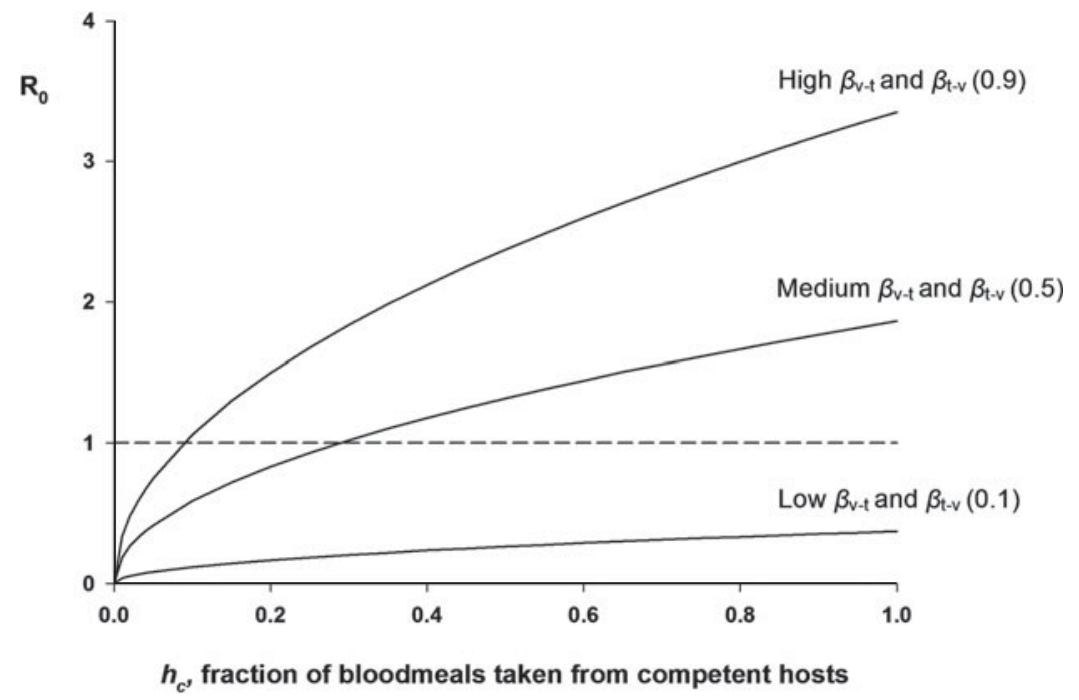

C

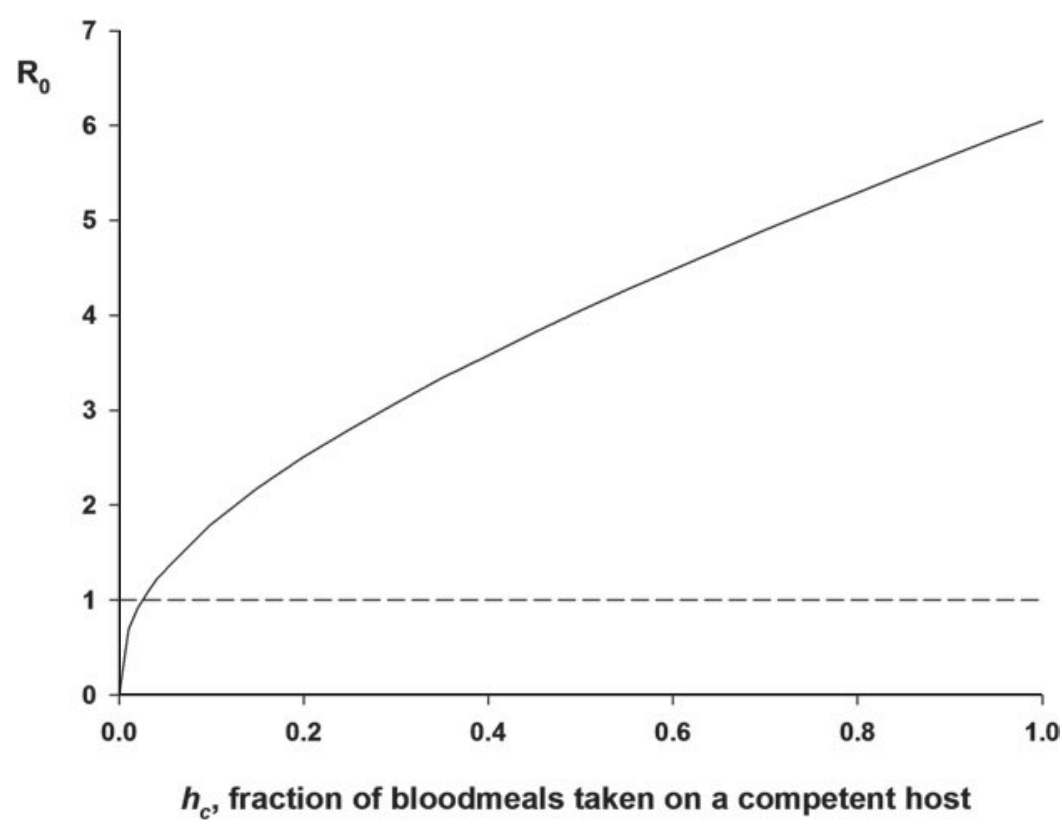

Fig. 1. $\mathrm{R}_{0}$ plotted as a function of $h_{c}$, the fraction of bloodmeals taken on a competent host, for (a) Babesia microti, (b) Anaplasma phagocytophilum (both under low, medium and high transmission efficiency scenarios) and (c) Borrelia burgdorferi s.l. using previously published transmission coefficients (cited by Hartemink et al. 2008). 
A

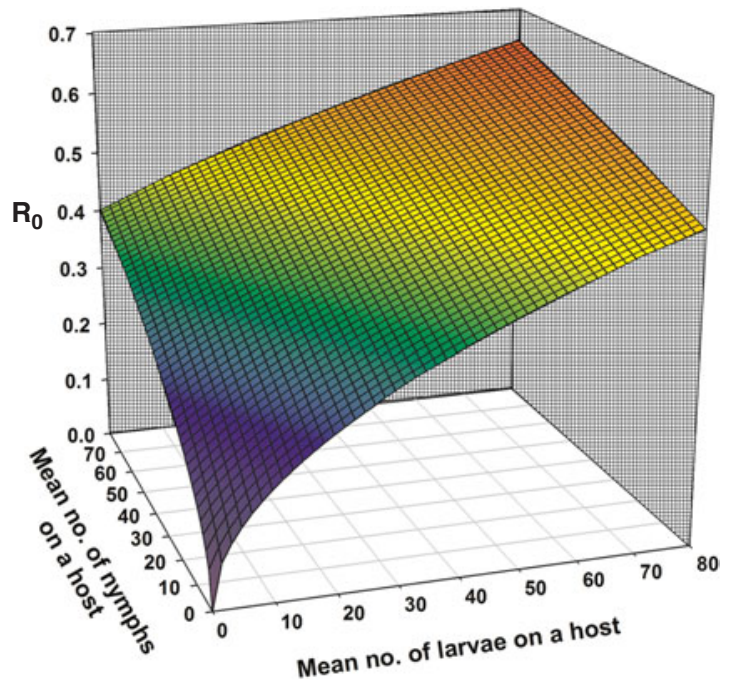

B

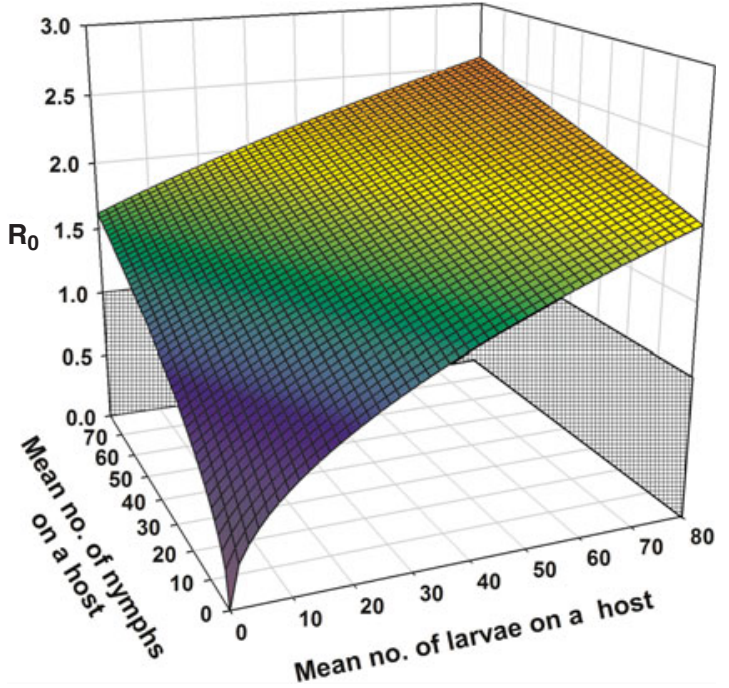

C

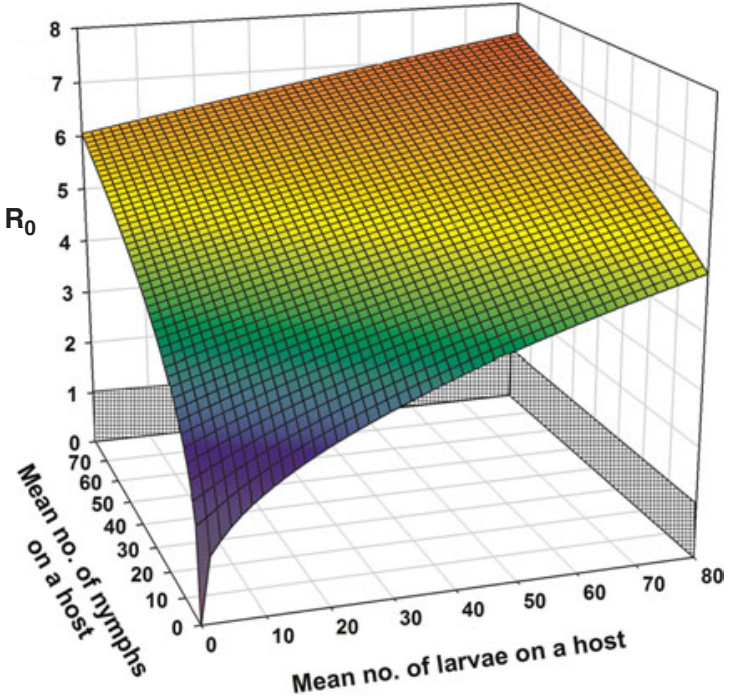

Fig. 2. Interaction of mean larval and nymphal abundance of Ixodes ricinus on Apodemus sylvaticus and $\mathrm{R}_{0}$ for (a) Babesia microti, (b) Anaplasma phagocytophilum and (c) Borrelia burgdorferi s.1. assuming a medium level transmission efficiency of 0.5 for $(a, b)$, previously and roe deer in Slovakia and a lamb from Norway sharing $98.0 \%$ sequence similarity (EU180065, EF442003 and EU240474, respectively). All percentage similarities are across 301 base pairs.

(b) B. burgdorferi s.l. Of the 20 ticks that tested positive for $B$. burgdorferi s.1. 13 were sequenced successfully. R6, R17, R21, R57, T5, T61 and TC64 were most closely related to the $B$. garinii genospecies (AB178361) sharing 96.4\%-98.2\% sequence similarity. TC33 and TC19 were most closely related to the B. afzelii-type strain (GQ369937) with $93 \cdot 2 \%$ and $98 \cdot 6 \%$ sequence similarity and L1, TC16, R64 and T1 were most closely related to the $B$. valaisiana genospecies (L30134) with 93·5\%-97·3\% similarity. Therefore, $85 \%$ of $B$. burgdorferi-positive samples successfully sequenced were bird-associated genospecies whilst $15 \%$ were associated with rodents. All percentage similarities are across 225 base pairs.

\section{Bloodmeal analysis}

A total of 170 questing I. ricinus nymphs collected from 4 sites were included in bloodmeal analysis, 83 of which yielded positive reactions. DNA from more than 1 host was found in $13 / 83$ positive reactions resulting in 96 host identifications made from 83 positive reactions. Birds were the most important hosts for $I$. ricinus nymphs feeding as larvae and were present in 51 out of 96 host identifications. Deer were the second most important hosts (18/96) followed by wood mice and pygmy shrews (both 11/96). Squirrels were the least important hosts for larval ticks, present in only 5 out of 96 host identifications. None of the ticks that tested positive for A. phagocytophilum yielded reactions in the bloodmeal analysis. Sixteen of the 20 nymphs that tested positive for B. burgdorferi s.1. were included in bloodmeal analysis. Of the $8 B$. burgdorferi s.l. positive samples identified as the $B$. valaisiana genotype by sequence analysis, 4 gave positive reactions all of which indicated that the ticks had previously fed on birds. Of the $3 \mathrm{~B}$. burgdorferi s.l. positive samples identified as $B$. garinii, 1 gave a positive host identification indicating that this tick had also fed on a bird. Neither of the samples identified as $B$. afzelii by sequence analysis gave positive host identifications. Two samples which gave positive host identifications were of mixed origin, both of which included a deer and shrew signal.

published transmission coefficients (cited by Hartemink et al. 1998) for (c) and $h_{c}=11 \cdot 45 \%$ for all 3 pathogens. Hatching indicates areas of the plot where $\mathrm{R}_{0}<1$. 
DISCUSSION

The basic reproduction number, $\mathrm{R}_{0}$, responded differently for each pathogen in response to the proportion of competent hosts on which $I$. ricinus fed and the mean abundance of larval and nymphal ticks on hosts. Values of $\mathrm{R}_{0}$ suggested that B. microti could not persist given the distribution of life-history stages of ticks on wood mice, even if the transmission coefficients were high, if ticks fed solely on competent reservoir hosts, or if tick larval and nymphal tick burdens were unrealistically high. This was supported by the absence of $B$. microt $i$ in wood mice and questing ticks when screened by PCR. The inability of B. microti to become established or persist in this system is likely to be a product of the short period of infectivity that this pathogen has for ticks of 1-4 days (Randolph, 1995).

In the case of $A$. phagocytophilum, the threshold value of $R_{0}$ was achieved, but only when the proportion of competent hosts on which I. ricinus had fed was greater than that of the current study or when the transmission coefficient was unrealistically high. A. phagocytophilum was not detected in small mammals but $A$. phagocytophilum was found in questing ticks. However, sequence analysis revealed that the strains were most closely related to those recovered from large mammals across Europe suggesting that other, large mammal, hosts of I. ricinus present at the study site were responsible for these infections. Moreover, Bown et al. (2009) observed that different $A$. phagocytophilum strains exist in discrete enzootic small mammal and large mammal cycles. The prevalence of infection of I. ricinus nymphs was low $(1 \cdot 12 \%)$ and the probability of a mouse feeding a nymph was also low $(2 \cdot 02 \%)$. Even if different strains of $A$. phagocytophilum were capable of utilizing both large and small mammals the probability of a nymph infected with A. phagocytophilum feeding on a mouse was extremely low $(0.02 \%$ or 1 in 5000$)$ making the spillover of A. phagocytophilum from larger to small mammals highly unlikely. Therefore, it is highly probable that the $A$. phagocytophilum strains present in the current study were involved in an ungulate-tick cycle and that no $A$. phagocytophilum cycles were present in wood mice.

In contrast to B. microti and A. phagocytophilum, the threshold value of $\mathrm{R}_{0}$ for $B$. burgdorferi s.l. was achieved rapidly, requiring $I$. ricinus to feed on a much smaller proportion of competent hosts than encountered in the current study $(2 \cdot 55 \%)$. This threshold value was reached using realistic transmission coefficients and required fewer larval and nymphal tick abundances to feed on mice than that recorded in the current study. Values of $R_{0}$ indicated that small mammals alone could maintain cycles of infection of $B$. burgdorferi s.l. without the need for alternative transmission hosts. s.l. This suggestion was at least partially supported by the identification of B. afzelii, a rodent-associated Borrelia genospecies (Kurtenbach et al. 2002), in questing ticks. However, the origin of the $B$. afzelii infections could not be determined by bloodmeal analysis. Squirrels are also competent reservoirs of this Borrelia genospecies (Craine et al. 1997) and it is possible that they were the origin of the infection.

Differences in the response of $\mathrm{R}_{0}$ between $B$. microti and $A$. phagocytophilum most likely lie in differences in the systemic infection duration. Clinical infections of $B$. microti have been detected for up to 31 days post-infection by PCR in the USA (Vannier et al. 2004). As previously mentioned, Randolph (1995) observed that in the actual period of infectivity for ticks feeding on an infected host is 1-4 days using British strains. A. phagocytophilum infections have been detected by PCR for up to 40 days post-infection (Telford et al. 1996) but the actual period of infectivity is unknown. If, like $B$. microti, the period of infectivity is much less than the period where the infection can be detected by PCR then the threshold value of $R_{0}$ would be more difficult to achieve and infection cycles of A. phagocytophilum less likely to develop.

The ability of $B$. burgdorferi s.l. to become established more readily in the wood mouse-tick system than other pathogens is a product of its relatively long systemic infection duration and the secondary route of infection available via efficient co-feeding transmission (Randolph et al. 1996).

As expected, wood mice were infected almost exclusively with larvae and only 3 nymphs were recovered. The resultant small nymph to larvae ratio $(1: 388)$ is comparable to those found elsewhere in

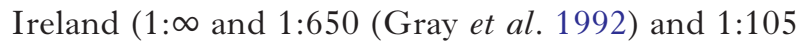
(Gray et al. 1999) but is generally much smaller than those recorded across the rest of Europe $(\min =1: 7$, $\max =1: 185$, mean $=1: 44, n=19)$ (Matuschka et al. 1991; Humair et al. 1993; Talleklint and Jaenson, 1994; Kurtenbach et al. 1995; Humair et al. 1999; Randolph and Storey, 1999; Randolph et al. 1999)). It has been suggested that climatic conditions, such as humidity and temperature, can determine the distribution of tick life stages on hosts (Randolph and Storey, 1999). Ticks are prone to desiccation and immature stages are more susceptible than adults due to their smaller surface area to volume ratio, higher metabolic rate and limited fat reserves (Randolph and Storey, 1999). As a result, different life stages quest at different heights in vegetation, with larvae questing close to the moist litter layer and nymphs and adults questing progressively higher (Gigon, 1985). Experimental data have shown that nymphs, when confronted by increasingly dry conditions, quest lower in vegetation and feed more frequently on small mammals (Randolph and Storey, 1999). Ireland has a temperate maritime climate and generally has higher levels of precipitation and lower temperatures 
than other locations across Europe (BIOCLIM variables; BIO12-annual precipitation and BIO1annual mean temperature, www.worldclim.org/ bioclim). Therefore, it is likely that nymphs in Ireland quest higher in vegetation than individuals in drier locations and, as a result, do not encounter small mammals as frequently. Low nymph to larvae ratios may limit the development of enzootic tickborne pathogen cycles in small mammals. However, the distribution of $I$. ricinus on small mammals is often over-dispersed and this must be taken into account when assessing if tick-borne pathogen cycles are likely to be present, or develop, in a given area (Nilsson and Lundqvist, 1978; Craine et al. 1995; Randolph et al. 1999). For example, Randolph et al. (1999) found that the same $20 \%$ of small mammal hosts fed $61 \%$ of larvae and $72 \%$ of nymphs whilst a similar observation was made in the current study ( $20 \%$ of hosts fed $72 \%$ of larvae and all nymphs). This coincident aggregated distribution has important implications for the transmission of tick-borne pathogens as it allows small numbers of nymphs to feed alongside, and potentially infect, large numbers of larvae (Randolph et al. 1999). Therefore, even small nymph to larvae ratios, such as those found in Ireland may be epidemiologically significant.

Sequence analysis indicated that 2 bird-associated genospecies of $B$. burgdorferi s.l. were also present in $I$. ricinus nymphs, $B$. valaisiana and $B$. garinii (Kurtenbach et al. 2002). Bloodmeal analysis revealed that birds were the most important hosts of larval $I$. ricinus and that ticks infected with $B$. valaisiana and $B$. garinii had previously fed on birds. Therefore, it is not surprising that birdassociated Borrelia genospecies were the most common infections present. Present data suggest that birds are important hosts of larval $I$. ricinus and have a more important role in the epidemiology of $B$. burgdorferi s.1. in Ireland than small mammals. This suggestion is supported by previous studies in Ireland that also found bird-associated Borrelia genospecies to be the most common Borrelia infections present in questing ticks and that wood mice were rarely infected with $B$. burgdorferi s.l. (Kirstein et al. 1997; Gray et al. 1999, 2000).

The current study highlights how individual variation in the ecological parameters of tick-borne pathogens and their vectors can greatly affect the probability of establishment and persistence of pathogens within a system. We believe the $R_{0}$ model of Hartemink et al. (2008) and the methods currently presented provide a potentially valuable tool in the control of tick-borne pathogens, allowing the identification of factors responsible for tick-borne pathogen persistence which could be utilized in management decisions. The view that small mammals have a more limited role in the epidemiology of tick-borne infections where nymphs of $I$. ricinus are rare on small mammals is supported.

\section{ACKNOWLEDGEMENTS}

A. Harrison was supported by a Ph.D. studentship from the Department of Agriculture and Rural Development (DARD), and access to field sites was kindly provided by the Forest Service of Northern Ireland. We thank Richard Birtles for access to facilities and Mathieu Lundy and Neil Reid for constructive discussion on the manuscript. This study was conducted in compliance with the ethical procedures of the Queen's University of Belfast.

\section{REFERENCES}

Anderson, R. M. and May, R. M. (1990). Modern vaccines: Immunisation and herd immunity. Lancet 335, 641-645.

Arthur, D. R. (1963). British Ticks. 1st Edn. Butterworths, London.

Bown, K. J., Begon, M., Bennett, M., Woldehiwet, Z. and Ogden, N. H. (2003). Seasonal dynamics of Anaplasma phagocytophila in a rodent-tick (Ixodes trianguliceps) system, United Kingdom. Emerging Infectious Diseases 9, 63-70.

Bown, K. J., Lambin, X., Ogden, N.H., Begon, M., Telford, G., Woldehiwet, Z. and Birtles, R. J. (2009). Delineating Anaplasma phagocytophilum ecotypes in coexisting, discrete enzootic cycles. Emerging Infectious Diseases 15, 1948-1954.

Bown, K. J., Lambin, X., Ogden, N.H., Petrovec, M., Shaw, S. E., Woldehiwet, Z. and Birtles, R. J. (2007). High-resolution genetic fingerprinting of European strains of Anaplasma phagocytophilum by use of multilocus variable-number tandem-repeat analysis. Fournal of Clinical Microbiology 45, 1771-1776.

Caraco, T., Glavanakov, S., Chen, G., Flaherty, J. E., Ohsumi, T. K. and Szymanski, B. K. (2002). Stage-structured infection transmission and a spatial epidemic: a model for Lyme disease. The American Naturalist $\mathbf{1 6 0}$, 348-359.

Courtney, J. W., Kostelnik, L. M., Zeidner, N.S. and Massung, R. F. (2004). Multiplex real-time PCR for detection of Anaplasma phagocytophilum and Borrelia burgdorferi. Fournal of Clinical Microbiology 42, 3164-3168.

Craine, N. G., Nuttall, P. A., Marriott, A.C. and Randolph, S. E. (1997). Role of grey squirrels and pheasants in the transmission of Borrelia burgdorferi sensu lato, the Lyme disease spirochaete, in the U.K. Folia Parasitologica 44, 155-160.

Craine, N. G., Randolph, S.E. and Nuttall, P.A. (1995). Seasonal variation in the role of grey squirrels as hosts of Ixodes ricinus, the tick vector of the Lyme disease spirochaete, in a British woodland. Folia Parasitologica 42, 73-80.

De La Fuente, J., Massung, R. F., Wong, S. J., Chu, F. K., Lutz, H., Meli, M., Von Loewenich, F. D., Grzeszczuk, A., Torina, A. and Caracappa, S. (2005). Sequence analysis of the msp4 gene of Anaplasma phagocytophilum strains. Fournal of Clinical Microbiology 43, 1309-1317. Diekmann, O., Heesterbeek, J. A. P. and Metz, J. A. J. (1990). On the definition and the computation of the basic reproduction ratio $\mathrm{R}_{0}$ in models for infectious diseases in heterogeneous populations. Fournal of Mathematical Biology 28, 365-382.

Duh, D., Petrovec, M. and Avsic-Zupanc, T. (2001). Diversity of Babesia infecting European sheep ticks (Ixodes ricinus). Fournal of Clinical Microbiology 39, 3395-3397.

Gern, L., Estrada-Pena, A., Frandsen, F., Gray, J. S., Jaenson, T. G., Jongejan, F., Kahl, O., Korenberg, E., Mehl, R. and Nuttall, P. A. (1998). European reservoir hosts of Borrelia burgdorferi sensu lato. Zentralblatt fur Bakteriologie: International Fournal of Medical Microbiology 287, 196-204.

Gern, L. and Rais, O. (1996). Efficient transmission of Borrelia burgdorferi between cofeeding Ixodes ricinus ticks (Acari: Ixodidae). Fournal of Medical Entomology 33, 189-192.

Ghosh, M. and Pugliese, A. (2004). Seasonal population dynamics of ticks, and its influence on infection transmission: A semi-discrete approach. Bulletin of Mathematical Biology 66, 1659-1684.

Gigon, F. (1985). Biologie d'Ixodes ricinus L. sur le Plateau Suisse-Une contribution à l'écologie de ce vecteur. Unpublished Ph.D. thesis, University of Neuchatel, France.

Gray, J., von Stedingk, L. V., Gurtelschmid, M. and Granstrom, M. (2002). Transmission studies of Babesia microti in Ixodes ricinus ticks and gerbils. Fournal of Clinical Microbiology 40, 1259-1263.

Gray, J. S. (2002). Biology of Ixodes species ticks in relation to tick-borne zoonoses. Wiener klinische Wochenschrift 114, 473-478. 
Gray, J. S., Kahl, O., Janetzki, C. and Stein, J. (1992). Studies on the ecology of Lyme disease in a deer forest in County Galway, Ireland. Fournal of Medical Entomology 29, 915-920.

Gray, J. S., Kirstein, F., Robertson, J. N., Stein, J. and Kahl, O. (1999). Borrelia burgdorferi sensu lato in Ixodes ricinus ticks and rodents in a recreational park in south-western Ireland. Experimental and Applied Acarology 23, 717-729.

Gray, J. S., Robertson, J. N. and Key, S. (2000). Limited role of rodents as reservoirs of Borrelia burgdorferi sensu lato in Ireland. European Fournal of Epidemiology 16, 101-103.

Harrison, A., Scantlebury, M. and Montgomery, W. I. (2010). Body mass and sex-biased parasitism in wood mice Apodemus sylvaticus. Oikos 119, 1099-1104.

Hartemink, N.A., Randolph, S.E., Davis, S.A. and Heesterbeek, J. A. P. (2008). The basic reproduction number for complex disease systems: Defining $\mathrm{R}_{0}$ for tick-borne infections. The American Naturalist 171, 743-754.

Hodzic, E., Borjesson, D. L., Feng, S. and Barthold, S. W. (2001). Acquisition dynamics of Borrelia burgdorferi and the agent of human granulocytic ehrlichiosis at the host-vector interface. Vector-Borne and Zoonotic Diseases 1, 149-158.

Hubálek, Z. and Halouzka, J. (1998). Prevalence rates of Borrelia burgdorferi sensu lato in host-seeking Ixodes ricinus ticks in Europe. Parasitology Research 84, 167-172.

Humair, P.F., Douet, V., Cadenas, F. M., Schouls, L. M., Van De Pol, I. and Gern, L. (2007). Molecular identification of bloodmeal source in Ixodes ricinus ticks using $12 \mathrm{~S}$ rDNA as a genetic marker. Fournal of Medical Entomology 44, 869-880.

Humair, P. F., Rais, O. and Gern, L. (1999). Transmission of Borrelia afzelii from Apodemus mice and Clethrionomys voles to Ixodes ricinus ticks: differential transmission pattern and overwintering maintenance. Parasitology 118, 33-42.

Humair, P. F., Turrian, N., Aeschilimann, A. and Gern, L. (1993). Borrelia burgdorferi in a focus of Lyme borreliosis: epizootiologic contribution of small mammals. Folia Parasitologica 40, 65-70.

Jones, L. D., Davies, C. R., Steele, G. M. and Nuttall, P. A. (1987). A novel mode of arbovirus transmission involving a nonviraemic host. Science 237, 775-777.

Karbowiak, G. (2004). Zoonotic reservoir of Babesia microti in Poland. Polish Fournal of Microbiology 53, 61-65.

Kirstein, F., Rijpkema, S., Molkenboer, M. and Gray, J. S. (1997). Local variations in the distribution and prevalence of Borrelia burgdorferi sensu lato genomospecies in Ixodes ricinus ticks. Applied and Environmental Microbiology 63, 1102-1106

Kurtenbach, K., De Michelis, S., Etti, S., Schäfer, S. M., Sewell, H. S., Brade, V. and Kraiczy, P. (2002). Host association of Borrelia burgdorferi sensu lato-the key role of host complement. Trends in Microbiology 10, 74-79.

Kurtenbach, K., Dizij, A., Seitz, H.M., Margos, G., Moter, S.E., Kramer, M. D., Wallich, R., Schaible, U. E. and Simon, M. M. (1994). Differential immune responses to Borrelia burgdorferi in European wild rodent species influence spirochete transmission to Ixodes ricinus L. (Acari: Ixodidae). Infection and Immunity 62, 5344-5352.

Kurtenbach, K., Kampen, H., Dizij, A., Arndt, S., Seitz, H., Schaible, U. E. and Simon, M. M. (1995). Infestation of rodents with larval Ixodes ricinus (Acari: Ixodidae) is an important factor in the transmission cycle of Borrelia burgdorferi sl in German woodlands. Fournal of Medical Entomology 32, 807-817

Liz, J.S., Anderes, L., Sumner, J.W., Massung, R. F., Gern, L., Rutti, B. and Brossard, M. (2000). PCR detection of granulocytic ehrlichiae in Ixodes ricinus ticks and wild small mammals in western Switzerland. Fournal of Clinical Microbiology 38, 1002-1007.

Matuschka, F. R., Fischer, P., Musgrave, K., Richter, D. and Spielman, A. (1991). Hosts on which nymphal Ixodes ricinus most abundantly feed. The American Fournal of Tropical Medicine and Hygiene 44, 100-107.

Milne, A. (1949). The ecology of the sheep tick, Ixodes ricinus L. Host relationships of the tick, Part 2 Observations on hill and moorland grazings in northern England. Parasitology 39, 173-197.

Nilsson, A. and Lundqvist, L. (1978). Host selection and movements of Ixodes ricinus (Acari) larvae on small mammals. Oikos 31, 313-322.

Norman, R., Bowers, R. G., Begon, M. and Hudson, P. J. (1999).

Persistence of tick-borne virus in the presence of multiple host species: tick reservoirs and parasite mediated competition. Fournal of Theoretical Biology 200, 111-118.

Ogden, N.H., Bown, K., Horrocks, B.K., Woldehiwet, Z. and Bennett, M. (1998). Granulocytic Ehrlichia infection in ixodid ticks and mammals in woodlands and uplands of the UK. Medical and Veterinary Entomology 12, 423-429.

Parola, P. (2004). Tick-borne rickettsial diseases: emerging risks in Europe. Comparative Immunology, Microbiology and Infectious Diseases 27, 297-304. Parola, P. and Raoult, D. (2001). Ticks and tick-borne bacterial diseases in humans: an emerging infectious threat. Clinical Infectious Diseases 32, 897928. doi: $10.1086 / 319347$

Randolph, S.E. (1995). Quantifying parameters in the transmission of Babesia microti by the tick Ixodes trianguliceps amongst voles (Clethrionomys glareolus). Parasitology 110, 287-295.

Randolph, S. E. (1998). Ticks are not insects: consequences of contrasting vector biology for transmission potential. Parasitology Today 14, 186192.

Randolph, S. E. (2004). Tick ecology: processes and patterns behind the epidemiological risk posed by ixodid ticks as vectors. Parasitology 129, $37-65$

Randolph, S. E. and Craine, N. G. (1995). General framework for comparative quantitative studies on transmission of tick-borne diseases using Lyme borreliosis in Europe as an example. Fournal of Medical Entomology 32, 765-777.

Randolph, S.E., Gern, L. and Nuttall, P. A. (1996). Co-feeding ticks: epidemiological significance for tick-borne pathogen transmission. Parasitology Today 12, 472-479.

Randolph, S. E., Miklisova, D., Lysy, J., Rogers, D. J. and Labuda, M. (1999). Incidence from coincidence: patterns of tick infestations on rodents facilitate transmission of tick-borne encephalitis virus. Parasitology 118, 177-186.

Randolph, S. E. and Storey, K. (1999). Impact of microclimate on immature tick-rodent host interactions (Acari: Ixodidae): implications for parasite transmission. Fournal of Medical Entomology 36, 741-748.

Rijpkema, S. G., Molkenboer, M. J., Schouls, L. M., Jongejan, F. and Schellekens, J. F. (1995). Simultaneous detection and genotyping of three genomic groups of Borrelia burgdorferi sensu lato in Dutch Ixodes ricinus ticks by characterization of the amplified intergenic spacer region between 5S and 23S rRNA genes. Fournal of Clinical Microbiology 33, 30913095.

Rosa, R. and Pugliese, A. (2007). Effects of tick population dynamics and host densities on the persistence of tick-borne infections. Mathematical Biosciences 208, 216-240.

Rosą, R., Pugliese, A., Norman, R. and Hudson, P. J. (2003). Thresholds for disease persistence in models for tick-borne infections including non-viraemic transmission, extended feeding and tick aggregation. Fournal of Theoretical Biology 224, 359-376.

Simpson, V. R., Panciera, R. J., Hargreaves, J., McGarry, J. W., Scholes, S. F. E., Bown, K. J. and Birtles, R. J. (2005). Myocarditis and myositis due to infection with Hepatozoon species in pine martens (Martes martes) in Scotland. The Veterinary Record 156, 442-446.

Snow, K. R. (1978). Identification of Larval Ticks Found on Small Mammals in Britain. 1st Edn. The Mammal Society, Reading, Berks, UK.

Stanzak, J., Gabre, R. M., Kruminis-Lozowska, W., Racewicz, M. and Kubica-Biernat, B. (2004). Ixodes ricinus as a vector of Borrelia burgdorferi sensu lato, Anaplasma phagocytophilum and Babesia microti in urban and suburban forests. Annals of Agriculture and Environmental Medicine 11, 109-114.

Talleklint, L. and Jaenson, T. G. T. (1994). Transmission of Borrelia burgdorferi sl from mammal reservoirs to the primary vector of Lyme borreliosis, Ixodes ricinus (Acari: Ixodidae), in Sweden. Fournal of Medical Entomology 31, 880-886.

Telford, S. R., Dawson, J.E., Katavolos, P., Warner, C. K., Kolbert, C.P. and Persing, D. H. (1996). Perpetuation of the agent of human granulocytic ehrlichiosis in a deer tick-rodent cycle. Proceedings of the National Academy of Sciences, USA, 93, 6209-6214.

Telford, S. R., Mather, T. N., Moore, S.I., Wilson, M. L. and Spielman, A. (2006). Incompetence of Deer as reservoirs of Borrelia burgdorferi. Annals of the New York Academy of Sciences 539, 429-430.

Vannier, E., Borggraefe, I., Telford, S. R., Menon, S., Brauns, T., Spielman, A., Gelfand, J. A. and Wortis, H. H. (2004). Age-associated decline in resistance to Babesia microti is genetically determined. The fournal of Infectious Diseases 189, 1721-1728. doi: 10.1086/382965. 
APPENDIX

Structure of the next generation matrix (a), a schematic version of the matrix indicating the location of the various transmission routes used by pathogens (b) and a list of equations used to calculate each element within the matrix (c) (taken from Hartemink et al. 2008). Equations utilize tick- and pathogen-specific parameters derived from the literature and the current study (Tables 1 and 2).

(a)

$$
\mathrm{K}=\left\{\begin{array}{rrrrr}
k_{11} & k_{12} & k_{13} & k_{14} & 0 \\
k_{21} & k_{22} & k_{23} & 0 & k_{25} \\
k_{31} & k_{32} & k_{33} & 0 & k_{35} \\
k_{41} & k_{42} & k_{43} & 0 & k_{45} \\
k_{51} & k_{52} & k_{53} & 0 & 0
\end{array}\right\}
$$

(b) (transovarial transovarial tra

$\left(\begin{array}{ccccc}\text { transovarial } & \text { transovarial } & \text { transovarial } & \text { transovarial } & 0 \\ \text { cofeeding } & \text { cofeeding } & \text { cofeeding } & 0 & \text { host } \rightarrow \mathrm{L} \\ \text { cofeeding } & \text { cofeeding } & \text { cofeeding } & 0 & \text { host } \rightarrow \mathrm{N} \\ \text { cofeeding } & \text { cofeeding } & \text { cofeeding } & 0 & \text { host } \rightarrow \mathrm{A} \\ \text { tick } \rightarrow \text { host } & \text { tick } \rightarrow \text { host } & \text { tick } \rightarrow \text { host } & 0 & 0\end{array}\right)$

(c) $k_{11}=s_{\mathrm{L}} s_{\mathrm{N}} s_{\mathrm{A}} E r_{\mathrm{A}}$,

$k_{12}=s_{\mathrm{N}} s_{\mathrm{A}} E r_{\mathrm{A}}$,

$k_{13}=s_{\mathrm{A}} E r_{\mathrm{A}}$,

$k_{14}=E r_{\mathrm{A}}$,

$k_{15}=0$,

$k_{21}=\left(s_{\mathrm{L}} \sigma_{\mathrm{LL}} \mathrm{C}_{\mathrm{LL}}+s_{\mathrm{L}} s_{\mathrm{N}} \sigma_{\mathrm{NL}} \mathrm{C}_{\mathrm{LN}}+s_{\mathrm{L}} s_{\mathrm{N}} s_{\mathrm{A}} \emptyset_{\mathrm{AL}} \mathrm{C}_{\mathrm{LA}}\right) h_{c}$,

$k_{22}=\left(s_{\mathrm{N}} \emptyset_{\mathrm{NL}} \mathrm{C}_{\mathrm{LN}}+s_{\mathrm{N}} s_{\mathrm{A}} \emptyset_{\mathrm{AL}} \mathrm{C}_{\mathrm{LA}}\right) h_{c}$,

$k_{23}=\left(s_{\mathrm{A}} \sigma_{\mathrm{AL}} \mathrm{C}_{\mathrm{LA}}\right) h_{c}$,

$k_{24}=0$,

$k_{25}=\frac{p_{\mathrm{L}} i N_{\mathrm{LH}}}{\mathrm{D}_{\mathrm{L}}}$

$k_{31}=\left(s_{\mathrm{L}} \sigma_{\mathrm{LN}} \mathrm{C}_{\mathrm{NL}}+s_{\mathrm{L}} s_{\mathrm{N}} \sigma_{\mathrm{NN}} \mathrm{C}_{\mathrm{NN}}+s_{\mathrm{L}} s_{\mathrm{N}} s_{\mathrm{A}} \varnothing_{\mathrm{AN}} \mathrm{C}_{\mathrm{NA}}\right) h_{c}$,

$k_{32}=\left(s_{\mathrm{N}} \emptyset_{\mathrm{NN}} \mathrm{C}_{\mathrm{NN}}+s_{\mathrm{N}} s_{\mathrm{A}} \emptyset_{\mathrm{AN}} \mathrm{C}_{\mathrm{NA}}\right) h_{c}$,

$k_{33}=\left(s_{\mathrm{A}} \sigma_{\mathrm{AN}} \mathrm{C}_{\mathrm{NA}}\right) h_{c}$,

$k_{34}=0$,

$k_{35}=\frac{p_{\mathrm{N}} i N_{\mathrm{NH}}}{\mathrm{D}_{\mathrm{N}}}$

$k_{41}=\left(s_{\mathrm{L}} \sigma_{\mathrm{LA}} \mathrm{C}_{\mathrm{AL}}+s_{\mathrm{L}} s_{\mathrm{N}} \emptyset_{\mathrm{NA}} \mathrm{C}_{\mathrm{AN}}+s_{\mathrm{L}} s_{\mathrm{N}} s_{\mathrm{A}} \varnothing_{\mathrm{AA}} \mathrm{C}_{\mathrm{AA}}\right) h_{c}$,

$k_{42}=\left(s_{\mathrm{N}} \emptyset_{\mathrm{NA}} \mathrm{C}_{\mathrm{AN}}+s_{\mathrm{N}} s_{\mathrm{A}} \emptyset_{\mathrm{AA}} \mathrm{C}_{\mathrm{AA}}\right) h_{c}$,

$k_{43}=\left(s_{\mathrm{A}} \emptyset_{\mathrm{AA}} \mathrm{C}_{\mathrm{AA}}\right) h_{c}$,

$k_{44}=0$,

$k_{25}=\frac{p_{\mathrm{A}} i N_{\mathrm{AH}}}{\mathrm{D}_{\mathrm{A}}}$

$k_{51}=\left(s_{\mathrm{L}} q_{\mathrm{L}}+s_{\mathrm{L}} s_{\mathrm{N}} q_{\mathrm{N}}+s_{\mathrm{L}} s_{\mathrm{N}} s_{\mathrm{A}} q_{\mathrm{A}}\right) h_{c}$,

$k_{52}=\left(s_{\mathrm{N}} q_{\mathrm{N}}+s_{\mathrm{N}} s_{\mathrm{A}} q_{\mathrm{A}}\right) h_{c}$,

$k_{53}=s_{\mathrm{A}} q_{\mathrm{A}} h_{c}$,

$k_{54}=0$,

$k_{55}=0$. 